\title{
ATRIBUIÇÕES DO ENFERMEIRO DE BORDO NO TRANSPORTE AEROMÉDICO EM TEMPOS DE PANDEMIA DA COVID 19
}

\author{
Márcio Soares de ALMEIDA ${ }^{1}$
}

\section{RESUMO}

A enfermagem é a profissão majoritária nos serviços de saúde, e a atuação do enfermeiro de bordo no transporte aeromédico em tempos de pandemia da Covid-19 enaltece a qualidade de mais esse espaço de atuação profissional. Objetivo: Descrever as atribuições de um enfermeiro de bordo no transporte aeromédico e a assistência de enfermagem em tempos de pandemia da Covid -19. Método: Relato de experiência de um enfermeiro que atua no serviço de transporte aeromédico em aeronaves de asas fixas, numa empresa privada, localizada no estado da Bahia, Brasil, durante os meses de abril de 2020 a março do ano de 2021. Resultados: As atribuições do enfermeiro de bordo perpassava pelas fases que antecede o voo, o transporte propriamente dito e a finalização do transporte. As peculiaridades do paciente acometido pela SARS-CoV-2 torna o transporte ainda mais desafiador, tendo em vista que a hipóxia é fator condicionado ao transporte aéreo. Considerações finais: As atribuições do enfermeiro eram centradas no pré-voo, voo e o póstransporte. A assistência de enfermagem ao paciente acometido pela Covid-19 possuía peculiaridades, tendo em vista que a hipóxia ocasionada pela altitude demanda ainda mais atenção ao paciente que já possui comprometimento respiratório significativo decorrente da doença em curso.

Palavras-chave: Enfermeiro de bordo, Aeromédico, Coronavírus.

\section{INTRODUÇÃO}

As atribuições do enfermeiro de bordo no transporte aeromédico em tempos de pandemia causada pelo novo Coronavírus elenca as fases que antecede o voo, a assistência no transporte propriamente dito e o pós-voo, sendo esta última quando o paciente é captado pela equipe de destino e todos os materiais e insumos são repostos para uma nova missão.

A enfermagem é a profissão majoritária nos serviços de saúde, sendo essencial na promoção à saúde e prevenção de agravos. No seu processo de formação, há particularidades que agregam ao cuidado dedicado aos pacientes um olhar e manejo que alcançam o âmbito físico, espiritual e psicoemocional do doente e o cuidar humanitário torna a profissão uma das mais éticas no campo da saúde (REYNOLDS, 2020). Nesse sentido, o reconhecimento do enfermeiro de bordo

\footnotetext{
${ }^{1}$ Enfermeiro. Especialista. Mestrando pela Universidade Federal da Bahia (UFBA)
} 
voltada para as atividades que realiza como membro da equipe multiprofissional do transporte aeromédico enaltece a qualidade de mais esse espaço de atuação profissional (SCUISSIATO et al., 2012).

No Brasil, a Resolução N 660/2021 do Conselho Federal de Enfermagem (COFEN), normatiza a atuação do enfermeiro na assistência direta e no gerenciamento do atendimento pré-hospitalar móvel e inter-hospitalar em veículo aéreo, respalda o exercício dessa segmento e fortalece o trabalho da enfermagem para constituir uma prática segura e de qualidade, direcionando ao (a) enfermeiro (a) o cuidado privativo (COFEN, 2021).

Ante ao exposto, esse trabalho tem como objetivo descrever as atribuições de um enfermeiro de bordo no transporte aeromédico e a assistência de enfermagem em tempos de pandemia da Covid -19 .

\section{METODOLOGIA}

Trata-se de um relato de experiência de um enfermeiro que atua no serviço de transporte aeromédico em aeronaves de asas fixas, numa empresa privada, localizada no estado da Bahia, Brasil. Este relato está fundamentado na descrição da percepção da prática desenvolvida pelo profissional de enfermagem no transporte inter-hospitalar de pacientes acometidos pela Covid-19, e discute as atribuições do enfermeiro de bordo na assistência ao paciente aerorremovido em tempos de pandemia causada pelo novo Coronavírus. As vivências profissionais se deram durante os meses de abril de 2020 a março do ano de 2021. Os dados foram apreendidos pelo autor a partir das memórias e de anotações de campo durante as vivências e posteriormente foram transcritos, organizados e descritos.

\section{RESULTADOS}

\section{Atribuições do enfermeiro de bordo no transporte aeromédico}

As atribuições do enfermeiro de bordo centrava-se no planejamento e organização de todo o transporte, de acordo com o paciente, elencado nas fases do pré-voo, o transporte propriamente dito e o momento pós-transporte. Na fase que antecede o voo, o enfermeiro provia todos os materiais e equipamentos necessários durante a missão, assim como verificava a funcionalidade dos aparelhos, preenchia check-list e escolhia a configuração interna da aeronave de forma a melhor atender o 


\section{CON \\ Cons}

perfil do paciente, pois eram transportados desde recém nascidos à adultos.

Posteriormente a isso, o enfermeiro, na preparação para iniciar o voo, deveria ter o maior conhecimento possível sobre o paciente a ser transportado e, ao chegar ao local da remoção, ainda em solo, era realizado, juntamente com o profissional médico, a avaliação inicial do paciente a fim de verificar as suas condições clínicas e hemodinâmicas. Passada esta etapa, o enfermeiro voltava-se para as possíveis necessidades assistenciais do paciente e o cuidado durante o transporte, pois certificava se todos os equipamentos estavam adequadamente fixados; mantinha o paciente bem posicionado na maca; observava a fixação de sondas, drenos e cateteres; instalava monitorização multiparamétrica; administrava medicamentos conforme solicitação e prescrição médica, além do cuidado holístico e centrado na humanização e segurança do paciente.

A fase pós voo, ou a finalização do transporte, começava com a transferência do paciente a equipe da ambulância terrestre, e terminava quando todos os materiais e equipamentos estavam repostos. Cabia, também, ao enfermeiro, organizar e finalizar os relatórios do voo, com os registros dos dados do paciente e o preenchimento das ocorrências, assim como higienizava os equipamentos utilizados, requeria a limpeza e desinfecção da aeronave e encaminhava para a esterilização e lavanderia todos os materiais que eram reutilizáveis.

\section{Assistência de Enfermagem ao paciente aerotransportado acometido pela Covid- 19}

A assistência de enfermagem ao paciente aerotransportado acometido pela Covid- 19 apresentava particularidades, tendo em vista as alterações fisiológicas ocasionadas pela altitude, principalmente a hipóxia, e o comprometimento respiratório que o paciente diagnosticado com a Covid 19 possuía (SILVA et al., 2021). O transporte demandava a equipe maior conhecimento técnico e científico sobre os possíveis distúrbios respiratórios, cardiovasculares, metabólicos e neurológicos que poderiam surgir como fatores negativos durante o voo.

Era necessário comunicação efetiva entre enfermeiro e médico que assistiam ao paciente, e as ações nas tomadas de decisão eram realizadas de forma consensual nas situações de emergências e ou rotineiras, pois era levado em consideração a alta exposição ao vírus e o consequente risco de contágio. O uso de Equipamentos de 


\section{CON

Proteção Individual (EPI), assim como a paramentação e desparamentação da equipe e tripulação, respeitava o protocolo institucional, os Procedimentos Operacionais Padrão (POP) e as recomendações para Operações Aeromédica envolvendo pacientes suspeitos ou confirmados de Infecção por SARS-CoV-2 (ABRAMED, 2020).

Nesse sentido, o enfermeiro planejava a assistência ao paciente diagnosticado com a Covid-19 ainda na fase do pré-voo, uma vez que é nesse etapa a checagem da funcionalidade de todos os equipamentos, como monitor e desfibrilador cardíaco, respirador portátil, bombas de infusão, sistema de aspiração, conferência dos medicamentos e insumos necessários. Também, além de certificar-se do tempo de voo, a quantidade de oxigênio disponível para o trajeto era de extrema relevância, pois conforme relatado por Guimarães (2020), é um ambiente que predispõe a hipóxia, a qual poderia ser agravada por um perfil de paciente que demandava maior consumo desse gás.

Por fim, a assistência de enfermagem era centrada de forma sistematizada, onde buscava-se as informações do paciente através do relatório médico obtido previamente, e dessa maneira eram traçadas as implementações necessárias para um transporte seguro e complementar, conduzindo o paciente para a unidade de destino o mais estável e seguro possível, e passava-se aos profissionais receptores a maior quantidade de informação sobre o doente, de forma concisa e assertiva, pautada no conhecimento científico mas também humanizado, fundamentado no cuidado, essência da enfermagem.

\section{CONSIDERAÇÕES FINAIS}

As atribuições do enfermeiro de bordo no transporte aeromédico em tempos de pandemia causada pela Covid-19 perpassava pelas fases que antecedia o voo, o transporte propriamente dito e a finalização do transporte. As peculiaridades do paciente acometido pela SARS-CoV-2 tornava o transporte ainda mais desafiador, tendo em vista que a hipóxia ocasionada pela altitude demanda ainda mais atenção ao paciente que já possuía comprometimento respiratório significativo decorrente da doença em curso, além da iminente exposição da equipe a um vírus com alto poder de infecção e disseminação. Assim, a assistência de enfermagem era sistematizada, reforçada pela utilização de check-list, POP's e recomendações dos órgão reguladores para o transporte aeromédico em tempos de pandemia. 


\section{REFERÊNCIAS}

ABRAMED. Associação Brasileira de Medicina de Emergência. Recomendações para Operações Aeromédicas envolvendo Pacientes Suspeitos ou Confirmados de Infecção por SARS-CoV-2. Disponível em:> http://abramede.com.br/wpcontent/uploads/2020/07/RECOMEDACOES-AEROMEDICO.pdf < Acesso em: 15 de junho de 2021.

COFEN. Conselho Federal de Enfermagem. RESOLUÇÃO COFEN N 660/2021. Altera a Resolução Cofen $n^{\circ}$ 656, de 17 de dezembro de 2020, que normatiza a atuação do enfermeiro na assistência direta e no gerenciamento do atendimento Pré-Hospitalar Móvel e Inter-hospitalar em veículo aéreo. Disponível em: >http://www.cofen.gov.br/resolucao-cofen-no-660-2021 85716.html < Acesso em 15 de junho de 2021.

GUIMARÃES, Clarissa Coelho Vieira. Transporte aéreo de pacientes: enfermagem militar na evacuação aeromédica. 2020. 91 f. Dissertação (Mestrado em Enfermagem) - Escola de Enfermagem Alfredo Pinto, Universidade Federal do Estado do Rio de Janeiro, Rio de Janeiro, 2020.

SCUISSIATO, D. R. et al. Compreensão de enfermeiros de bordo sobre seu papel na equipe multiprofissional de transporte aeromédico. Rev Bras Enferm, Brasília, v. 65, n. 4, p. 614-29, jul./ago., 2012.

REYNOLDS, N. R. Ano dos Profissionais de Enfermagem e Obstetrícia: ativando o potencial e o poder da enfermagem. Rev. latinoam. enferm. v. 28, e. 3279, 2020

SILVA, C. C. et. al. Covid-19: Aspectos da origem, fisiopatologia, imunologia e tratamento: uma revisão narrativa. Revista Eletrônica Acervo Saúde. v. 13, n. 2. DOI: https://doi.org/10.25248/REAS.e6542.2021. 2021. Disponível em: > https://acervomais.com.br/index.php/saude/article/view/6542/4310 < Acesso em: 15 de junho de 2021. 